\title{
Sistemas de memória: relação entre memória de trabalho e linguagem sob uma abordagem neuropsicolinguística
}

Sistemas de memoria: relación entre memoria de trabajo y lenguaje desde una perspectiva neuropsicolingüística Les systèmes de mémoire : le rapport entre la mémoire de travail et le langage au-delà d'une approche neuropsycholinguistique Memory systems: relation between working memory and language in a neuropsycholinguistic approach

\section{Tânia M. Netto ${ }^{1,3}$, Mirella L. Prando ${ }^{2}$, Cristina E. I. Wong 2 , Janice R. Pureza ${ }^{2}$, Lilian C. Scherer $^{2}$, Rochele P. Fonseca, \& J. Landeira-Fernandez ${ }^{3}$}

\author{
${ }^{1}$ Universidade Federal do Rio de Janeiro, Brasil. ${ }^{2}$ Pontifícia Universidade Católica do Rio Grande do Sul, Brasil. ${ }^{3}$ Pontifícia \\ Universidade Católica do Rio de Janeiro, Brasil.
}

Resumo

Revisou-se a classificação dos sistemas de memória enfocando a memória de trabalho (MT) e sua relação com a linguagem. A interação dos níveis de complexidade da linguagem com os sistemas mnemônicos é indubitável. A principal relação da MT com a linguagem reside em dois componentes: alça fonológica e buffer episódico. Nessa área, são necessários estudos que detalhem as relações entre discurso, pragmática e a MT, principalmente sobre o funcionamento do seu principal componente, o executivo central.

Palavras-chave: Memória de trabalho; linguagem; neuropsicolinguística.

\section{Resumen}

Se revisan las clasificaciones de los sistemas de memoria focalizando en la memoria de trabajo (MT)y su relación con el lenguaje. Es indudable la existencia de una interacción entre los niveles de complejidad del lenguaje y los sistemas mnésicos. La principal relación entre lenguaje y MT reside en dos componentes: el bucle fonológico y el buffer episódico. Es necesario llevar a cabo investigaciones que aborden y detallen las relaciones entre discurso, pragmática y MT, enfatizando esencialmente sobre el funcionamento de su componente principal: el ejecutivo central.

Palabras clave: Memoria de trabajo; lenguaje; neuropsicolingüística.

\section{Résumé}

La taxonomie des systèmes de mémoire est révisée en mettant l'accent sur la mémoire de travail (MT) et son rapport avec le langage. Tous les niveaux de complexité du langage interagissent avec les composantes de la MT. Le rapport principal avec la MT réside dans deux systèmes : la boucle phonologique et le "buffer" épisodique. Des recherches plus approfondies restent nécessaires pour comprendre clairement le rapport entre le discours, particulièrement la partié liée à la pragmatique, et la MT, spécifiquement avec le fonctionnement de l'exécutif central.

Mots-clés : Mémoire de travail ; langage ; neuropsycholinguistique.

Artigo recebido: 20/12/2011; Artigo revisado: 28/12/2011; Artigo aceito: 30/12/2011.

Tânia Maria Netto. Núcleo de Neuropsicologia Clínica e Experimental (NNCE), Programa de Pós-Graduação em Psicologia Clínica (Neurociências) da Pontifícia Universidade Católica do Rio de Janeiro, PUC-Rio e do PPG em Neurorradiologia da UFRJ. Colaboradora do GNCE, PUCRS.

Mirella Liberatore Prando. Programa de Pós-Graduação em Psicologia da Pontifícia Universidade Católica do Rio Grande do Sul, PUCRS, membro do Grupo Neuropsicologia Clínica e Experimental (GNCE), PUCRS.

Cristina Elizabeth Izábal Wong, Programa de Pós-Graduação em Psicologia da PUCRS, membro do GNCE, PUCRS.

Janice da Rosa Pureza, Programa de Pós-Graduação em Psicologia da PUCRS. Membro do GNCE, PUCRS.

J. Landeira-Fernandez, Programa de Pós-Graduação em Psicologia Clínica (Neurociências) da PUC-Rio e da UNESA. Coordenador do NNCE, PUC-Rio.

Lilian Cristine Scherer, Faculdade de Letras e do Programa em Pós-Graduação em Letras - Linguística, PUCRS.

Correspondências relacionadas a esse artigo devem ser enviadas a: Tânia Maria Netto. PUC-Rio. Rua Marques de São Vicente 225 - Departamento de Psicologia - Gávea, Rio de Janeiro - RJ, 22451-041. Brasil. E-mail:

E-mail: netto.tm@gmail.com

DOI: $10.5579 / \mathrm{rnl} .2011 .0087$ 
Memory systems taxonomy was reviewed focusing on working memory (WM) and its relationship with language. Levels of language complexity interact with WM components. The main relation between language and WM lies in two systems: phonological loop and the episodic buffer. It is necessary to conduct research to delineate the relationships between discourse, mainly to what concerns to pragmatic issues, and working memory, especially to what concerns the functioning of its main component: central executive.

Keywords: Working memory; language; neuropsycholinguistics.

No contexto da neuropsicologia em consonância com a neuropsicolinguística, diversos estudos têm procurado entender a interação entre dois construtos de grande importância durante o desenvolvimento humano: memória e linguagem. Profissionais especialistas em linguagem, tais como, lingüistas e fonoaudiólogos, vem buscando cada vez mais conhecimentos complementares sobre os sistemas da memória, com o objetivo de entender a interação entre essas duas funções cognitivas. Esse conhecimento tem sido, muitas vezes, adquirido por meio de estudos sobre o desempenho de indivíduos em testes neuropsicológicos, que empregam tarefas verbais e visuais, administrados em diferentes tipos de amostras, tanto saudáveis como clínicas (Haschimoto et al., 2010). No entanto, as pesquisas ainda são incipientes nas áreas de Psicolingüística e Fonoaudiologia. Um conhecimento aprofundado e atualizado sobre a memória, principalmente sobre a memória de trabalho (MT), bem como sua interação com os componentes da linguagem, torna-se essencial para promover estudos aplicados nessa área. Na tentativa de preencher essa lacuna, a presente revisão teórica, visa responder as seguintes questões: 1) De que forma os diferentes níveis de complexidade da linguagem interagem com os sistemas mnemônicos?, 2) Como se dá a demanda de MT quando a complexidade lingüística é mais requerida? e principalmente, 3) No que se refere ao principal componente da MT, o executivo central, como este participa nos diferentes componentes linguísticos? Objetivando responder essas perguntas, um panorama de modelos cognitivos da memória considerados mais influentes na literatura será apresentado, dando maior ênfase ao sistema da MT.

Graças aos estudos com pacientes amnésicos, hoje se sabe que a memória não é um sistema único, mas sim uma combinação complexa de vários subsistemas (Baddeley et al., 2009; Wilson, 2009). Tais estudos observaram que indivíduos com amnésias, decorrentes de traumas ou doenças, apresentavam desempenho mnemônico adequado em certas atividades, mas não em outras (Willingham \& Goedert, 2001). Um exemplo relatado por Baddeley (2009a), o caso de Clive, ilustra essa questão. Clive, um músico, maestro de um dos maiores corais de Londres, ficou incapacitado por uma amnésia causada por doença. Ele não conseguia ler um livro ou seguir um programa de televisão, mas conseguia conduzir seu coral, quando o visitava, da mesma forma como antes de ficar amnésico.

Devido à complexidade dos sistemas mnemônicos, vários modelos foram desenvolvidos, objetivando explicar o funcionamento da dinâmica entre eles. Esses modelos buscam explicar a interação entre as etapas de processos mnemônicos, como, codificação, armazenamento e evocação de informações, e também processamentos mnemônicos, tais como, analise, manipulação, combinação e agrupamento de informações, sendo que alguns deles baseiam-se em propriedades específicas, tais como: 1) tempo de retenção e 2) conteúdo de informações armazenadas (Ferreres, 2005).
No que concerne à variável tempo de retenção, um dos modelos mais conhecidos é o de Atkinson e Shiffrin (1971). Este explica a memória, como um sistema, dividido em três categorias: 1) memória sensorial, responsável pelos processos perceptivos, que armazena informações por um tempo menor do que um quarto do segundo; 2) memória de curto prazo, que retém informações por não mais do que alguns segundos, exceto quando ocorre um processo de repetição, e 3) memória de longo prazo, que mantém informações gravadas, por minutos, dias, ou anos (Wilson, 2009). No entanto, as informações que chegam à memória de longo prazo podem perder-se por esquecimento, interferência ou pela combinação de ambos (Atkinson \& Shiffrin, 1968).

Na Figura 1, pode-se observar uma representação gráfica da classificação dos sistemas de memória quanto ao tempo.

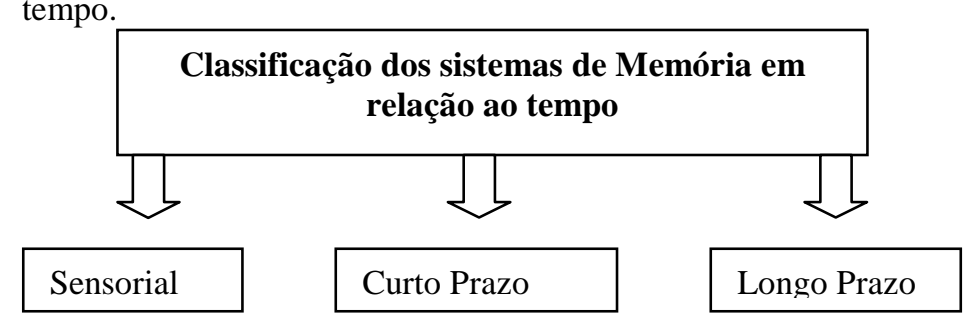

Figura 1. Tipos de memória quanto ao tempo de armazenamento.

A memória de longo prazo foi classificada por Squire (1986) de acordo com o seu conteúdo de informação armazenada em dois tipos: 1) explícita ou declarativa e 2) implícita ou não declarativa. A memória explícita (declarativa) define-se pela capacidade de evocar fatos e eventos de forma consciente, ou seja, de forma intencional (Baddeley, 2009a). Permite evocar informações, compará-las e confrontá-las com informações novas e aquelas mais consolidadas, fornece suporte ao processo de codificação e suas representações armazenadas são flexíveis, proporcionando assim uma maneira de modelar o mundo externo, de forma verdadeira ou falsa (Squire, 2004).

Essa memória foi classificada em dois subsistemas por Tulving (1972): o episódico e o semântico. O subsistema episódico permite ao indivíduo codificar, armazenar e recuperar acontecimentos específicos em um determinado tempo e lugar (Tulving, 1972, 2002). O semântico, por sua vez, codifica, armazena e recupera conhecimentos gerais sem basear-se no marcador do tempo.

De forma mais específica, a memória episódica está vinculada a capacidade de relembrar de acontecimentos específicos, bem como, experiências pessoais que é chamada memória autobiográfica (Tulving, 1972). Ela adquire informações derivadas das seguintes perguntas: $O$ quê? Quando? e onde? (Clayton \& Dickinson, 1998; Nyberg, et al., 1996). Além disso, essa memória requer três sistemas básicos: 1) codificação de determinada experiência diferenciada das outras já obtidas; 2) armazenamento do evento por um longo período de tempo, e 3) busca e evocação de determinado episódio codificado (Baddeley, 2009b). 
De acordo com Tulving (2002), a memória episódica é mais vulnerável a disfunções neuronais do que as outras e indivíduos com déficits nessa memória tendem a sofrem prejuízos no seu cotidiano. Tais déficits podem ser subdivididos em verbais, visuais e de reconhecimento (Wilson, 2009).

Em contrapartida, o subsistema semântico está relacionado a conhecimentos atemporais, tais como gerais e conceptuais (Baddeley, 2009b; Sternberg, 2008; Willingham \& Goedert, 2001). Esse subsistema permite processar informações sobre fatos do mundo em um amplo sentido e incluem conhecimentos e crenças elaboradas pelo próprio individuo (Ferreres, 2005). De um modo geral, ele refere-se ao conhecimento do mundo externo do qual lembramos na ausência de qualquer relato aprendido (Gazzaniga; Ivry; Mangun, 2006). É também responsável pelo armazenamento de conhecimentos gerais, significado das palavras, aparência visual e cores dos objetos (Tulving,1972). Além disso, possui um vasto armazenamento de informações sobre os significados, aparências, sons, cheiros e texturas dos objetos. Não requer conhecimento de quando essa informação foi obtida e nem onde (Wilson, 2009 p. 5). Para que informações sejam armazenadas na memória semântica é necessário que elas passem inicialmente pela memória episódica (Cermak \& O’Connor, 1983).

Em complementaridade a esses sistemas, a memória implícita (não declarativa) também evoca informações decorrentes da memória de longo prazo, mas de uma forma diferente, por meio de performance e de um sistema não acessível à consciência (Taussik \& Wagner, 2006). Ela envolve processos cognitivos aprendidos em uma variedade de habilidades motoras e cognitivas (Gazzaniga et al., 2006). A memória implícita tem sido classificada em quatro subtipos: 1) habilidades procedurais; 2) pré-ativação (priming); 3) hábitos; e 4) condicionamento (Sternberg, 2008).

A memória procedural está relacionada com a capacidade de memorizar a execução de tarefas essencialmente motoras que envolvem rotinas, como por exemplo, dirigir um carro (Wilson, 2009). O sistema de representação perceptiva, priming, age dentro de um sistema perceptual de palavras e objetos. Refere-se à resposta frente a um estímulo ou à habilidade de identificá-lo, a partir do resultado da exposição prévia deste estímulo (Gazzaniga et al., 2006; Lussier; Flessas, 2000; Moscovitch, 1992). Os hábitos são criados através da memorização por repetição de conhecimentos e comportamentos básicos para realizar tarefas do dia-a-dia (Squire \& Kandel, 2003). Para finalizar a classificação das memórias implícitas, o condicionamento é uma forma de aprendizado associativo, que solidifica-se após repetições de no mínimo dois estímulos pareados (Squire \& Kandel, 2003).

Pacientes que sofrem de amnésia possuem geralmente seus sistemas explícitos, principalmente $o$ episódico, alterados; no entanto os implícitos se mantêm, na maioria dos casos, preservados. Esse conhecimento auxilia no planejamento de avaliações e programas de reabilitação neuropsicológicas (Wilson, 2009) e de intervenções linguísticas no meio educacional.

Os tipos de memória quanto ao conteúdo podem ser representados conforme a Figura 2.

\section{Memória de Trabalho (MT)}

O último modelo mnemônico a ser apresentado nessa breve revisão crítico-reflexiva é o da MT. Para alguns autores esse sistema inclui a memória de curto-prazo (Cowan, 2008), mas, para outros, refere-se apenas aos aspectos relacionados à atenção da memória de curto prazo (Engle, 2002). Uma revisão sistemática nessa área discorda do uso do termo memória de curto prazo e MT como sendo sinônimos. Justifica-se que a MT representa um sistema que atua de forma mais complexa por relacionar-se com diferentes tipos de atividades cognitivas, diferindo assim da memória de curto-prazo (Rodrigues \& Befi-Lopes, 2009).

O termo MT foi empregado previamente para definir um tipo de sistema responsável pelo planejamento e execução de comportamentos (Cowan, 2008). addeley e Hitch (1974) propuseram que essa memória era composta por mais de um sistema. Dessa forma, deu-se origem ao Modelo da MT (Baddeley, 1986), definida como um sistema ativo, a partir do qual o indivíduo possui uma capacidade de armazenar informação por um tempo curto e limitado, mas suficiente para manipular tal informação durante a realização de tarefas mais complexas. Inicialmente, sugeriu-se que esse modelo constituía-se de três subsistemas, um dos quais - o executivo central - exerce a função de coordenar e manipular, com a ajuda dos processos relacionados à atenção, dois subsistemas auxiliares: a alça fonológica e o esboço visuo-espacial ( Cowan, 2008, Baddeley, 2009c).

O componente alça fonológica tem como função armazenar as informações auditivas e verbais por meio de um processo de recapitulação articulatória de curto prazo, tempo suficiente para que essas informações sejam processadas e utilizadas por meio de ações (Baddeley, 1986, 2003). No que se refere ao componente visuoespacial, informações são obtidas e manipuladas em forma de imagens visuais e espaciais.

No final da década de 1990, o papel do subsistema executivo central passou a ser investigado de forma mais profunda e a partir desses estudos foi proposto que suas funções eram inteiramente baseadas em um sistema de controle atencional, excluindo-se a capacidade de armazenamento (Baddeley \& Logie, 1999). No entanto, o modelo ainda não respondia como se dava a combinação de códigos verbais e visuais nas representações multidimensionais da memória de longo prazo. Além disso, este modelo mostrava evidências de que o armazenamento temporário de conteúdos parecia exceder a capacidade dos subsistemas verbal e visoespacial, demonstrando claramente a retenção de passagens do discurso (Baddeley, 2003). Devido a essa questão, Baddeley (2000) propôs um terceiro subsistema auxiliar, o retentor (buffer) episódico, que tem como função integrar vários domínios, tais como, visuais, verbais e perceptuais, decorrentes dos subsistemas, alça fonológica e esboço visuoespacial, com a memória de longo prazo (episódica e semântica) e transformá-los em um episódio único de forma que faça sentido (Baddeley, 2009a).

Recentemente, Baddeley (2009c) verificou que a MT utiliza componentes de processamento das funções executivas. Parte dessa conclusão deu-se pelo fato de que o componente executivo central e apenas um controlador atencional ativado concomitantemente com os outros subcomponentes responsáveis pelo armazenamento temporário, durante a 
execução de tarefas cognitivas. O retentor episódico, por ser responsável pela integração de informações mais complexas

\section{Classificação quanto ao Conteúdo}

(Sistemas Múltiplos)
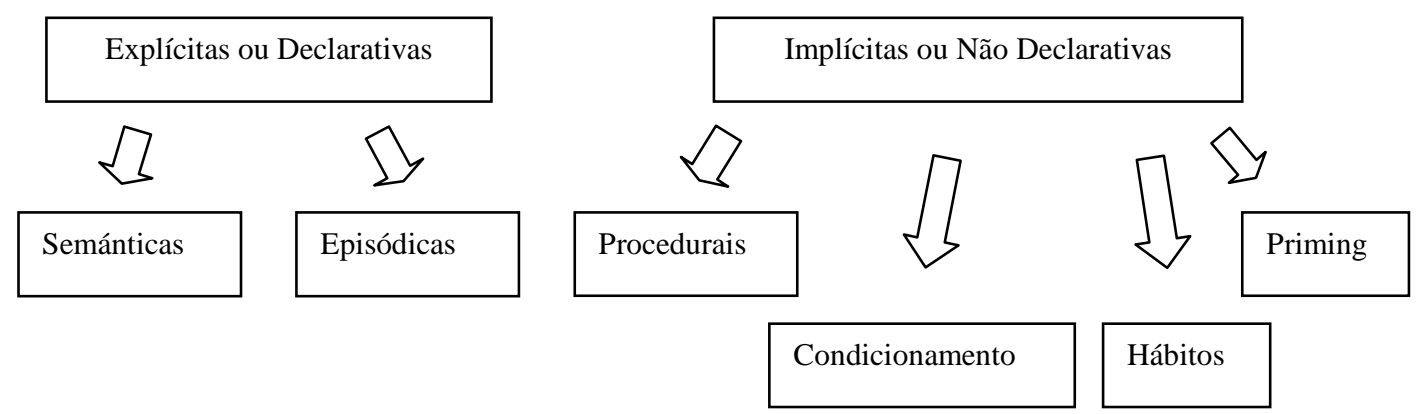

Figura 2. Representação gráfica dos tipos de memória quanto ao conteúdo (construída para este artigo)

de fontes diferentes, consegue reter cerca de quatro combinações de informações em um código multidimensional. Além disso, exerce também a função de integrar a informações decorrentes dos outros subsistemas com aquelas da memória de longo prazo. Cada uma dessas fontes de informações utiliza um código diferente que pode ser integrado em um único episódio de forma coerente. Por fim, observou-se que informações podem ser evocadas a partir do retentor episódico por meio de mecanismos conscientes (Baddeley, 2009c).

\section{Relação entre MT e linguagem}

Embora a relação entre estes processos pareça óbvia para linguistas e fonoaudiólogos, da vertente de conhecimento sobre linguagem, e para psicólogos cognitivos e neuropsicólogos, com conhecimento predominante sobre memória, parece ainda haver pouca literatura consistente sobre esta interface. Algumas evidências têm mostrado que a MT tem implicações no processamento da linguagem e que a presença de déficits em alguns de seus subsistemas, principalmente no da alça fonológica, pode influenciar esse processamento (Alloway \& Archibald, 2008). Do mesmo modo, a linguagem estando alterada, pode influenciar de sobremaneira o processamento da MT, evidente nos resultados de testes neuropsicológicos de desempenho cognitivo da memória de trabalho. De acordo com o resultado de alguns desses estudos, Baddeley (2003) tem evidenciado a grande importância da alça fonológica na aprendizagem da língua materna na infância. Além dessas implicações, durante o desenvolvimento típico da linguagem, déficits na MT podem alterar o curso dessa aquisição.

Diante desse quadro, pesquisas têm procurado analisar quais são os efeitos e as relações entre a MT e a linguagem, utilizando-se tarefas verbais e visuais, abrangendo diferentes amostras, tanto saudáveis, como clínicas (Haschimoto et al., 2010). Geralmente, as tarefas desses estudos analisam a relação entre a habilidade de repetição de não palavras (palavras sem significado) e o tamanho do vocabulário (Gupta, 2009). Além disso, o estudo da relação entre a MT e linguagem é amplamente abordado em estudos sobre as habilidades no processamento da leitura (Swanson, Zheng \& Jerman, 2009), na aquisição de uma segunda língua (Stowe, \&
Sabourin, 2005), e no bilinguismo (Hasegawa, Carpenter, Just, 2002).

As correlações entre a MT e o desenvolvimento normal da linguagem em crianças têm sido relatadas com freqüência na literatura (Adams \& Gathercole, 1996, 2000; Ardila \& Rosselli, 1994; Daal et al, 2008; Gathercole, Willis, Baddeley, \& Emslie, 1994; Baddeley, 2003). No entanto, estudos também têm evidenciado essa relação quando há prejuízo da linguagem (Adams, Clarke, \& Haynes, 2009; Adams \& Gathercole, 2000; Ellis-Weismer \& Evans, 2002; Gathercole, Tiffany, Briscoe, \& Thorn, 2005; Marton \& Schwartz, 2003; Montgomery, 2002; Pickering \& Gathercole, 2004; Schuchardt et al., 2008). Devido à relevância do tema para os estudos neuropsicológicos e neuropsicolinguísticos, há um crescente interesse no conhecimento sobre o avanço da capacidade mnemônica em crianças e como ela pode afetar o desenvolvimento linguístico infantil (Sternberg, 2008). Os achados de uma revisão sistemática sobre a avaliação da MT fonológica em crianças em desenvolvimento normal, desde a década de oitenta, demonstraram uma relação entre o conhecimento fonológico, lexical e a MT fonológica em crianças (Rodrigues \& Befi-Lopes, 2009). No entanto, no presente momento, há ainda uma necessidade de estudos sobre as relações entre os outros componentes da MT e as suas relações com a linguagem, principalmente no que tange ao nível linguístico mais complexo, o discurso oral e escrito, com e sem demanda de processamento pragmáticoinferencial. Sob esta perspectiva, acredita-se que o avanço nas habilidades de linguagem oral, principalmente, no discurso narrativo e conversacional, esteja fortemente relacionado às funções da memória, principalmente à MT e à memória episódica, contando com a participação, em diferentes graus, principalmente dos componentes executivo central, alça fonológica e buffer episódico. Na Figura 3, pode-se visulaizar para fins de representação gráfica uma adaptação do modelo de MT de Baddeley salientando-se a interação entre diversas funções cognitivas, a MT propriamente dita e a linguagem.

Estudos internacionais afirmam que a compreensão de frases e de textos é dependente da capacidade da MT e que para compreender um texto a MT é requerida e ativada para que seja possível a construção de significados (Clifton \& 
Duffy, 2001; Van Den Broek, Young, Tzeng, \& Linderholm, 1999). Isso se deve ao fato de que textos são mais longos,

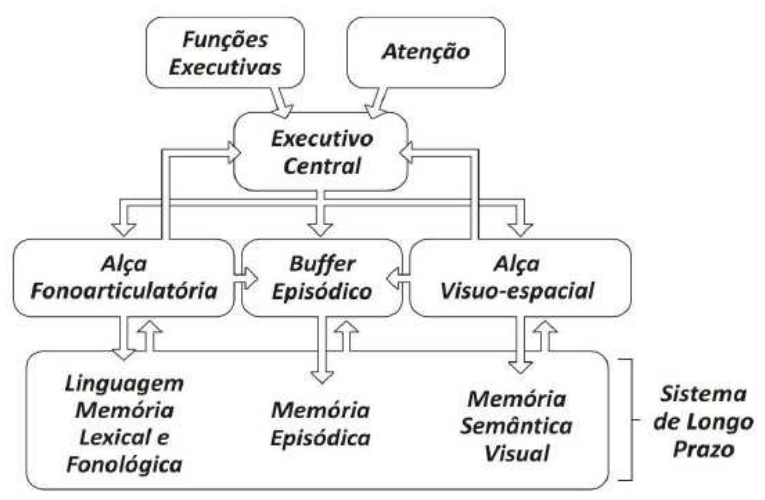

Figura 3. Representação da relação da MT com a Linguagem (construída para este artigo)

complexos e demandam assim uma representação semântica interativa. As informações presentes ou sugeridas pelo texto são modificadas a partir da reativação de informações antigas, de conhecimento de mundo, as quais vão sendo integradas às informações recebidas. Em outras palavras, a MT conecta as informações recebidas por meio da leitura do texto com o conhecimento prévio (incluindo o linguístico), armazenado na memória de longo prazo, enquanto integra todos os segmentos do texto. A MT é a responsável por estes processos, sendo considerada necessária de acordo com os diferentes modelos de compreensão da linguagem, bem como nos modelos de leitura. Limitações e déficits na MT estariam associados à habilidades deficitárias de compreensão de texto (Kintsch, 1988; Van Den Broek et al., 1999). A MT, com sua função de armazenamento temporal e manipulação de informação, além de participar na compreensão da linguagem, também torna-se essencial na aprendizagem, raciocínio e solução de problemas (Vuontela, 2008). Nota-se, então, que os componentes mais ativos da MT com o aumento da complexidade da unidade linguístic aprocessada são o buffer episódico e eo executivo central, estando estes predominantemente em ação na compreensão e produção do discurso, requerendo, ainda, componentes executivos das funções executivas conforme maior for o grau de processamento inferencial pragmático.

Entretanto, não há, ainda, um consenso na literatura, principalmente no âmbito nacional, sobre as relações entre diferentes sistemas da MT, episódica verbal e os diferentes componentes de linguagem oral. A escassez de instrumentos para as avaliações de componentes mnemônicos na população infantil pode justificar esta falta de análise de alguns processamentos cognitivos como adjacentes e complementares ao desenvolvimento da linguagem. Além disso, o fato de a linguagem ser mais estudada sob a ótica linguística do que a neuropsicológica pode ter contribuído para este caráter ainda incipiente.

\section{Considerações Finais}

A partir da reflexão teórica proposta neste artigo foi possível verificar que a literatura internacional, assim como a nacional, porém em menor frequência, abordam as interrelações existentes entre os construtos memória e linguagem. Embora os domínios cognitivos sejam dissociados, eles interagem entre si, de forma que a memória influi na linguagem, assim como a linguagem influi na memória, fortalecendo, desta forma, a necessidade de um entendimento mais sistemático, consolidado e profundo sobre a relação dessas funções. No entanto, os estudos empíricos relacionados a esse tema enfocam predominantemente a participação da memória fonológica ou alça fonológica da MT no desenvolvimento da linguagem. Além disso, esses estudos relatam que falhas na memória podem impactar o curso normal do seu desenvolvimento. Apoiando-se na conceitualização atual da MT de que esse domínio cognitivo é responsável por armazenar e manipular informações necessárias para que ocorra uma atividade cognitiva complexa (Baddeley, 2009), fica evidente a sua ativa participação no processamento da linguagem, no qual diversas atividades complexas estão envolvidas. Outros componentes da MT, assim como da memória episódica, porém, ainda são pouco discutidos e correlacionados à linguagem. Quanto à linguagem e seus componentes, o estudo dessas relações parece estar mais dirigido à fonologia e à semântica, com alguns trabalhos enfatizando habilidades linguísticas mais complexas, relacionadas à sintaxe, ao discurso e à pragmática.

É importante considerar, em investigações futuras, a conexão desses dois domínios cognitivos, linguagem e memória, com os processos executivos. A compreensão acerca das funções executivas e das suas relações com desempenho em tarefas de compreensão e expressão verbal torna-se fundamental para corroborar a idéia da complexidade na inter-relação desses processos cognitivos. A flexibilidade cognitiva, o planejamento, a organização, a seleção e a manutenção de estratégias cognitivas, além do monitoramento de informações são funções necessárias para o processamento linguístico oral e escrito.

Considerando-se o fato de que diferentes áreas da ciência como a Linguística, a Fonoaudiologia e, aparentemente em menor grau pela maior dedicação a experimentos com outros processos cognitivos, a Psicologia Cognitiva, tem a linguagem como um dos seus principais objetos de estudo, torna-se relevante a interface com a Neuropsicologia e Neuropsicolinguística. Uma maior busca da colaboração advinda dessas relações poderá contribuir com novos procedimentos em avaliação e técnicas de intervenções fonoaudiológica, neuropsicológica e neuropsicolinguistica, tanto na área clínica, como na científica e educacional, bem como para a ampliação de modelos de processamento envolvidas nos diferentes componentes e níveis da linguagem.

\section{REFERÊNCIAS}

Acheson, D. J., Hamidi, M., Binder, J. R. \& Postle, B. R. (2010). A common neural substrate for language production and verbal working memory. Journal of Cognitive Neuroscience, 1-10.

Adams, A.M. \& Gathercole, S. E. (1996). Phonological working memory and spoken language development in young children. The Quarterly Journal of Expirimental Psychology, 49a (1), 216-233.

Adams, A. M. \& Gathercole, S. E. (2000). Limitations in working memory: implications for language development. International Journal of Language and Communication Disorders, 35 (1), 95-116.

Adams, C., Clarke, E. \& Haynes, R. (2009). Inference and sentence comprehension in children with specific or pragmatic language Impairments. International Journal of Language and Communication Disorders, 44 (3), 301-318.

Alloway, T. P., \& Archibald, L. M. (2008). Working memory and learning in children with developmental coordination disorder and specific language impairment. Journal of Learning Disabilities, 41, 251-262.

Atkinson, R. C. \& Shiffrin, R. M. (1968). Human memory: A proposed system and its control processes. In K. W. Spence \& J. T. Spence (Eds.). The Psychology of Learning and Motivation: Advances in Research and Theory, New York: Academic Press. 
Baddeley, A. (1986). Working Memory, Oxford: Clarendon Press.

Baddeley, A. D., \& Emslie, H. (1994, 2003). The children's test of communication Disorders, 36, p. 189-208.

Baddeley, A., Eysenck, M., \& Anderson, M. C. (2009). Memory, New York: Psychology Press.

Baddeley, A. (2009a). What is Memory? In: A. Baddeley, M. W. Eysenck, M. C. Anderson (Eds.), Memory, New York: Psychology Press.

Baddeley, A. (2009b). Episodic memory: organizing and remembering. In: A. Baddeley, M. W. Eysenck, \& M. C. Anderson A. (Eds.), Memory (93-112). New York: Psychology Press.

Baddeley, A. (2009c). Working Memory. In: A. Baddeley, M. W. Eysenck \& M. C. Anderson (Eds.), Memory, New York: Psychology Press.

Baddeley, A. \& Hitch, G. J. (1974). Working Memory. In: G. A. Bower (Ed.), Recent advances in learning and motivation. New York: Academic Press.

Baddeley, A. D., \& Logie, R. H. (1999). Working memory: The multiplecomponent model. In A. Miyake \& P. Shah (Eds.), Models of working memory, New York: Cambridge University Press.

Baddeley, A. \& Wilson, B. A. (2002). Prose recall and amnesia: implications for the structure of working memory. Neuropsychología, 40, 17371743.

Berman, R. A. (2008). The psycholinguistics of developing text construction. F. Child Lang. 35, p. 735-771.

Casalini, C., Brizzolara, D., Chilosi, A., Cipriani, P., Marcolini, S., Pecini, C., Roncoli, S., \& Burani, C. (2007). Non-word repetition in children with specific language impairment: a deficit in phonological working memory or in long-term verbal knowledge? Cortex, 43, 769-776.

Cermak, L. S. \& O'Connor, M. (1983). The anterograde and retrograde retrieval ability of a patient with amnesia due to encephalitis. Neuropsychologia, 21 (3), 213-234.

Clayton, N. S., \& Dickinson, A. (1999). Scrub jays remember when as well as where and what food items they cached. Journal of Comparative Psychology, 113, 403-416.

Clifton, C., \& Duffy, S. (2001). Sentence comprehension: roles of linguistic structure. Annual Review of Psychology, 52, 167-196.

Cowan, N. (2008). What are the differences between long-term, short-term, and working memory? Progress in Brain Research, 169, 323-338.

Dodwell, K., \& Bavin, E. L. (2008). Children with specific language impairment: an investigation of their narratives and memory. International Journal of Language and Communication Disorders, 43(2), 201-218.

Ellis-Weismer, S. \& Evans, J. (2002). The role of processing limitations in early identification of specific language impairment. Topics in Language Disorders, 22, 15-29.

Engle, R. W. (2002). Working Memory Capacity as Executive Attention. Published by Blackwell Publishing Inc., 11 (1), 2002.

Ferreres, A. R. (2005). Estructuras, procesos y fases temporales de la memoria. In: Cerebro y memoria: El caso HM y el enfoque neurocognitivo de la memoria (1a Ed.). Buenos Aires: Tekné.

Gathercole, S. E., Tiffany, C., Briscoe, J., Thorn, A. S. C., \& Alspac Team. (2005). Developmental consequences of poor phonological shortterm memory function in childhood: a longitudinal study. Journal of Child Psychology and Psychiatry, 46, 598-611.

Gathercole, S. E., Willis, C. S., Baddeley, A. D., \& Emslie, H. (1994). The children's test of nonword repetition: A test of phonological working memory. Memory, 2 (2), 103-127.

Gazzaniga, M. S., Ivry, R. B. \& Mangun, G. R. (2006). Neurociência Cognitiva: a biologia da mente (2da Ed.). Artmed.

Gupta, P., \& Tisdale, J. (2009). Does phonological short-term memory causally determine vocabulary learning? Toward a computational resolution of the debate. Journal of Memory and Language, 61, 481502 .

Hasegawa, M., Carpenter, P. A., \& Just, M. A. (2002). An FMRI study of bilingual sentence comprehension and workload. Neuroimage, 15, 647-660.

Hashimoto, R.-I., Lee, K. U., Preus, A., McCarley, R. W., \& Wible, C. G. (2010). An FMRI study of functional abnormalities in the verbal working memory system and the relationship to clinical symtoms in chonic schizophrenia. Cerebral Cortex, 20, p. 46-60.

Kintsch, W. (1988). The role of knowledge in discourse comprehension: a construction-integration model. Psychological Review, 95(2), 163182.

Lussier, F. \& Flessas, J. (2000). Neuropsychologie de l'enfant. Trubles développmentaux et de l'apprentissage, Paris: Solal.

Marton, K., \& Schwartz, R. G. (2003). Working memory capacity limitations and language processes in children with specific language impairment. Journal of Speech Language and Hearing Research, 46, 1138-1153.
Montgomery J. W. (2002). Understanding the language difficulties of children with specific language impairments: does verbal working memory matter? Am J Speech Lang Pathol., 11, 77-91.

Montgomery, J. W. (2003). Working memory and comprehension in children with specific language impairment: what we know so far. Journal of Communication Disorders, 36, 221-231.

Moscovitch, M. (1992). A neuropsychological model of memory and consciousness. In: L. R. Squire, \& N. Butters, Neuropsycholgy of Memory (2nd Ed.). New York: The Guilford Press.

Nyberg, L. (1996). General and specific brain regions involved in encoding and retrieval of events: what, where, and when. Proceedings of the National Academy of Sciencies U. S. A., 93, 11280-11285.

Pickering, S. J. \& Gathercole, S. E. (2004). Distinctive Working Memory Profiles in Children with Special Educational Needs. Educational Psychology, 24 (3).

Puyuelo, M. (2007). Comunicação e Linguagem. desenvolvimento normal e alterações no decorrer do ciclo vital In. M. Puyuelo, \& J. Rondal, Manual de desenvolvimento e alterações da linguagem na criança e no adulto. Artmed, POA.

Rodrigues, A., \& Befi-Lopes, D. M. (2009). Phonological working memory and its relationship with language development in children (original title: Memória operacional fonológica e suas relações com o desenvolvimento da linguagem infantil). Pró-Fono Revista de Atualização Científica, 21(1), p.63-68.

Rosselli, M. \& Ardila, A. (2003). The impact of culture and education on non-verbal neuropsychological measurements: a critical review. Brain and Cognition, 52, 326-333.

Rosselli-Cock, M., Matute, V., E., Ardila-Ardila, A., Botero-Gómez, V. E., Tangarife, Salazar, G. A., Echverría-Pulido, S. E., Arbalaez-Giraldo, C., Mejía-Quintero, M., Méndez, L. C., Villa-Hurtado, P.C., Ocampo-Agudelo, P. (2004). Evaluación neuropsicológica infantil (ENI): una bateria para evaluación de niños entre 5 y 16 años de edad. Estudo normativo colombiano. Revista de Neurología, 38(8), 720-731.

Squire, L. (2004). Memory systems of the brain: A brief history and current perspective. Neurobiology of Learning and Memory, 82, 171-177.

Squire, L. R. (1986). Mechanisms of memory. Science, 232 (4578), 16121619.

Sternberg, R. (2008). Psicologia Cognitiva. Porto Alegre: Artmed.

Stowe, L., \& Sabourin, L. (2005). Imaging the processing of a second language: Effects of maturation and proficiency on the neural processes involved. International Review of Applied Linguistics in Language Teaching, 43, 329-354.

Swanson, H.L., Zheng,X., Jerman, O. (2009). Working Memory, Short-Term Memory, and Reading Disabilities: A Selective Meta-Analysis of the Literatura, 42(3), 260-287.

Taussik, I., Wagner, G. P. (2006). Memória explicita e envelhecimento. In: M. A. Parente (Org., Cognição e envelhecimento. Porto alegre: Artmed.

Tulving, E. (2002). Epsisodic Memory: From Mind to Brain. Annu. Rev. Psychol, 53, 1-25.

Tulving, E. (1972). Episodic and Semantic memory. In: E. Tulving, \& W. Donalson, (Eds.). Organization of memory. New York: Academic Press.

Van Der Broek, P., Young, M., Tzeng, Y., \& Linderholm, T. (1999). The landscape model of reading. In H. Van Oostendorp \& S. R. Goldman (Eds.), The construction of mental representations during reading, Mahwah, NJ: Laurence Erlbaum Associates Inc.

Vountela, V., Steenari, M.-R., Aronen, E. T., Korvenoja, A. Aronen, H. J., \& Carlson, S. (2009). Brain activation and deactivation Turing location and color working memory tasks in 11-13- year-old children. Brain and Cognition, 69, 56-64.

Willingham, D. B., Goedert, K. (2001). The role of taxonomies in the study of human memory. Cognitive, Affective \& Behavioral Neuroscience, 1(3), p. 250-265.

Wilson, B. (2009). Memory. New York: The Guilford Press.

Winocour, G., Moscovitch, M., \& Bontempi, B. (2010). Memory formation and long-term retention in humans and animals: convergence towards a transformation account of hippocampal-neocortical interactions, Neuropsychologia, 48, 2339-2356. 